American J. of Engineering and Applied Sciences 2 (2): 388-392, 2009

ISSN 1941-7020

(C) 2009 Science Publications

\title{
Robust Position Controller for a Permanent Magnet Synchronous Actuator
}

\author{
${ }^{1}$ Chams-Eddine Feraga, ${ }^{1}$ Abdelkrim Moussaoui, ${ }^{2}$ Abdallah Bouldjedri and ${ }^{2}$ Ali Yousfi \\ ${ }^{1}$ Department of Electrical Engineering, University of Guelma, B.P. 401, 24000, Algeria \\ ${ }^{2}$ Department of Electrical Engineering, University of Annaba, B.P. 12, Annaba, 23000, Algeria
}

\begin{abstract}
Problem statement: The present study investigated with the application of a robust control scheme to improve the performance of a simplified indirect field oriented for small power surface mounted Permanent Magnet (PM) synchronous actuators. Approach: The suggested model was implemented using a simplified state feedback with no need to measure the current values to compute the control algorithm. Results: The current values were estimated by an accurate prediction model estimated from real input/output data. The suggested control scheme was enabling the possibility to perform a position controller by using only a position sensor. Conclusion: The performance of the controller was evaluated and validated by digital simulation using SIMNON package and the usefulness of the suggested method was proved.
\end{abstract}

Key words: Field oriented control, synchronous actuator, position control

\section{INTRODUCTION}

Field oriented control allows to achieve high performance motion control with ac actuators ${ }^{[1-3]}$. This control strategy usually needs a fast control of the actuator stator phase currents. This is not easy to perform for surface mounted PM synchronous machines since the time constants associated with the evolution of the stator currents are very small (with an order of magnitude of a few milliseconds).

One solution which has been widely used consists of controlling these currents with analogue current loops ${ }^{[3]}$. However, unwanted interactions between these loops can appear which are related to the couplings existing between the phases of the machine.

Such interactions can be avoided by controlling the Park components of the currents since it is then possible to ensure a decoupling of the current loops ${ }^{[4]}$.

This study describes a simplified digital position control system for a small power rare earth permanent magnet synchronous actuator. Field orientation is performed in open loop by using an appropriate decoupling state feedback to keep the direct axis component of the stator current equal to zero. This decoupling feedback is computed with a predicted value of the quadrature axis current, so no current measurement is needed and the only sensor used is a digital position encoder.

Furthermore, it will also be shown that by using in the decoupling state feedback, an estimated value of the current instead of a measured one improves the robustness of the system against parameter uncertainties. The performance of the suggested system has been validated by digital simulations.

\section{MATERIALS AND METHODS}

Actuator modeling: The Park equations of a PM synchronous actuator without damper windings are:

$$
\begin{aligned}
& \mathrm{U}_{\mathrm{d}}=\mathrm{R}_{\mathrm{a}} \mathrm{i}_{\mathrm{d}}+\frac{\mathrm{dL}_{\mathrm{d}}}{\mathrm{dt}} \mathrm{i}_{\mathrm{d}}-\mathrm{P} \omega \mathrm{L}_{\mathrm{q}} \mathrm{i}_{\mathrm{q}} \\
& \mathrm{U}_{\mathrm{q}}=\mathrm{R}_{\mathrm{a}} \mathrm{i}_{\mathrm{q}}+\frac{\mathrm{dL}_{\mathrm{q}}}{\mathrm{dt}} \mathrm{i}_{\mathrm{q}}+\mathrm{P} \omega \mathrm{L}_{\mathrm{d}} \mathrm{i}_{\mathrm{d}}+\mathrm{K}_{\mathrm{T}} \omega \\
& \mathrm{T}_{\mathrm{em}}=\mathrm{K}_{\mathrm{T}} \mathrm{i}_{\mathrm{q}}+\mathrm{P}\left(\mathrm{L}_{\mathrm{d}}-\mathrm{L}_{\mathrm{q}}\right) \mathrm{i}_{\mathrm{d}} \mathrm{i}_{\mathrm{q}}
\end{aligned}
$$

Where:

$\mathrm{R}_{\mathrm{a}} \quad=$ The resistance of an armature winding

$\mathrm{L}_{\mathrm{d}}, \mathrm{L}_{\mathrm{q}}=$ The self inductances of the $\mathrm{d}$ and $\mathrm{q}$ armature equivalent windings

$\mathrm{K}_{\mathrm{T}} \quad=$ The torque constant

$\omega \quad=$ The rotor angular speed

$\theta \quad=$ The position

$2 \mathrm{P}=$ The number of poles

The corresponding block diagram is given in full line in Fig.1. In this Fig. $1 \mathrm{~T}$ is the load torque, $\mathrm{J}$ is the inertia of the actuator rotor and of the mechanical load, $\mathrm{K}$ is the viscous torque coefficient, $\mathrm{s}$ is the Laplace operator.

Corresponding Author: Chams-Eddine Feraga, Department of Electrical Engineering, University of Guelma, B.P. 401, 24000, Algeria 


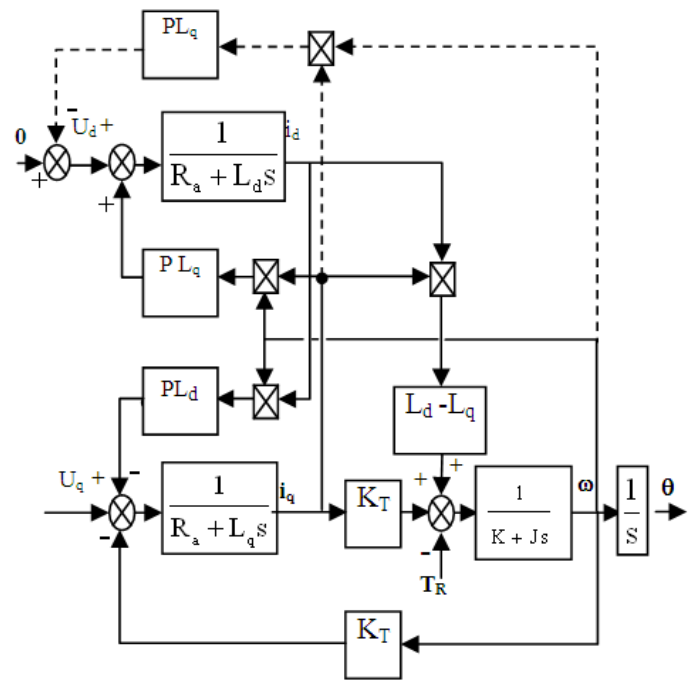

Fig. 1: Block diagram of a PM synchronous actuator

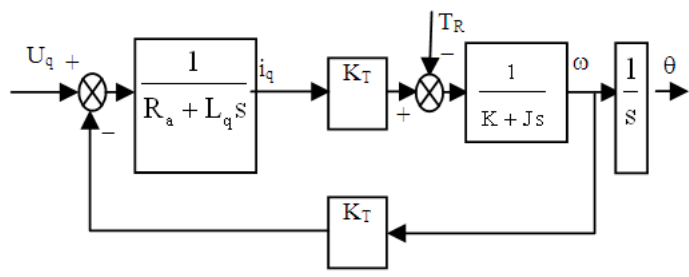

Fig. 2: Block diagram of the $\mathrm{q}$ axis after decoupling

The surface mounted rare earth permanent magnet synchronous actuators which are considered in this study have very low values of armature d axis and $q$ axis inductances, which makes it possible to ignore the electrical time constants $L_{d} / R_{a}$ and $L_{q} / R_{a}$.

Control strategy: It can be seen from Fig. 1 that, if the $\mathrm{d}$ axis current is equal to zero ${ }^{[5,6]}$, the block diagram of the synchronous actuator becomes similar to that of a DC machine as far as concern the position control (Fig. 2). This can be performed in open loop by introducing an appropriate state feedback (shown in broken line in Fig. 1). According to this state feedback the $\mathrm{d}$ axis voltage must be equal to:

$\mathrm{U}_{\mathrm{d}}=-\mathrm{P} \omega \mathrm{L}_{\mathrm{q}} \mathrm{i}_{\mathrm{q}}$

In the proposed control algorithm, the computation of $U_{d}$ is performed by using an estimated value of $i_{s q}$ instead of a measured one. This value is deduced from the rotor speed and from the value of the control voltage $\mathrm{U}_{\mathrm{q}}$ by neglecting the electrical time constant:

$\mathrm{i}_{\mathrm{q}}=\frac{\mathrm{U}_{\mathrm{q}}-\mathrm{K}_{\mathrm{T}} \omega}{\mathrm{R}_{\mathrm{a}}}$

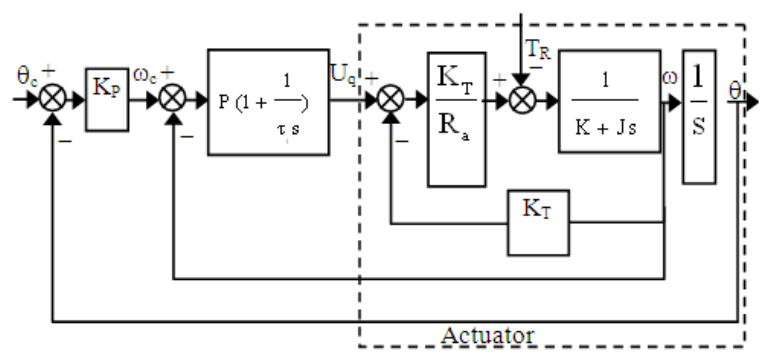

Fig. 3: Block diagram of the position control

The position controller generates the control voltage $\mathrm{U}_{\mathrm{q}}$. It comprises a PI speed regulator in cascade with a position proportional regulator. This structure is shown in Fig. 3 where the electrical time constant of the $\mathrm{q}$ axis has been neglected.

The controller shown in Fig. 3 can be seen as a PID position controller (with no derivative action on the position reference) without compensation of the motor back e.m.f. Because of this last feature this controller is very robust ${ }^{[7,8]}$.

It should be noted that the controller shown in Fig. 3 must to be robust against variations of inertia and load torque, but also against an imperfect decoupling of the $\mathrm{d}$ axis from the $\mathrm{q}$ axis due to uncertainties on the parameters and to the discretization inherent in every digital controller.

Robustness of the $i_{d}$ control: As we try to keep $i_{d}$ equal to zero in open loop, an error on parameter $\mathrm{L}_{\mathrm{q}}$ implies an error on $i_{d}$. This error can be easily computed in steady state.

Effect of an error on $\mathbf{L}_{q}$ : In the case of an error on $L_{q}$, the following expression is obtained in function of the speed, current $\mathrm{i}_{\mathrm{q}}$ and error $\Delta \mathrm{L}_{\mathrm{q}}$ on $\mathrm{L}_{\mathrm{q}}$.

if the decoupling (3) is computed with a measured value of $i_{q}$ :

$$
\mathrm{i}_{\mathrm{d}}=\frac{-\mathrm{P} \omega \Delta \mathrm{L}_{\mathrm{q}}}{\mathrm{R}_{\mathrm{a}}} \mathrm{i}_{\mathrm{q}}
$$

if the decoupling (3) is computed with an estimated value of $i_{q}$ :

$$
i_{d}=\frac{-P \omega \Delta L_{q}}{R_{a}+\frac{P^{2} \omega^{2} L_{q}^{*} L_{d}}{R_{a}}} i_{q}
$$

Effect of an error on $\mathbf{R}_{\mathrm{a}}$ : An error on the parameter $R_{a}$ does not affect the value of current $i_{d}$ in steady state if the decoupling is achieved with a measured value of 
$\mathrm{i}_{\mathrm{q}}$. It is not the case if the decoupling is achieved with an estimated value of $i_{q}$, but the error on current $i_{d}$ remains very small. This error is given in steady state by the following expression $\left(\mathrm{R}_{\mathrm{a}}{ }^{*}\right.$ is the estimated value of $R_{a}$ ):

$$
i_{d}=\frac{-P \omega L_{q}\left(1-\frac{R_{a}}{R_{a}^{*}}\right)}{R_{a}+\frac{P^{2} \omega^{2} L_{q} L_{d}}{R_{a}^{*}}} i_{q}
$$

\section{RESULTS}

The behaviour of the system has been simulated for the rare earth permanent magnet synchronous actuator whose parameters are shown in Table 1.

Figure 4 shows the speed $\omega$, the currents $i_{d}, i_{q}, i_{q}$ estimate and the tensions $\mathrm{U}_{\mathrm{d}}$ and $\mathrm{U}_{\mathrm{q}}$. The point of current $i_{q}$ appearing at the first moments of simulation is due to the delay caused by the computing time of the microprocessors.

Figure 5 shows that the response of the current $i_{q}$ (and thus of the couple) is slower and that the error on the current $i_{d}$ during the transients is larger than in the simulation of Fig. 4. It is obvious from Fig. 4 and 5 that the effectiveness of the $i_{d}$ control in open loop is greatly improved by the use of an estimated value of $i_{q}$ instead of a measured one.
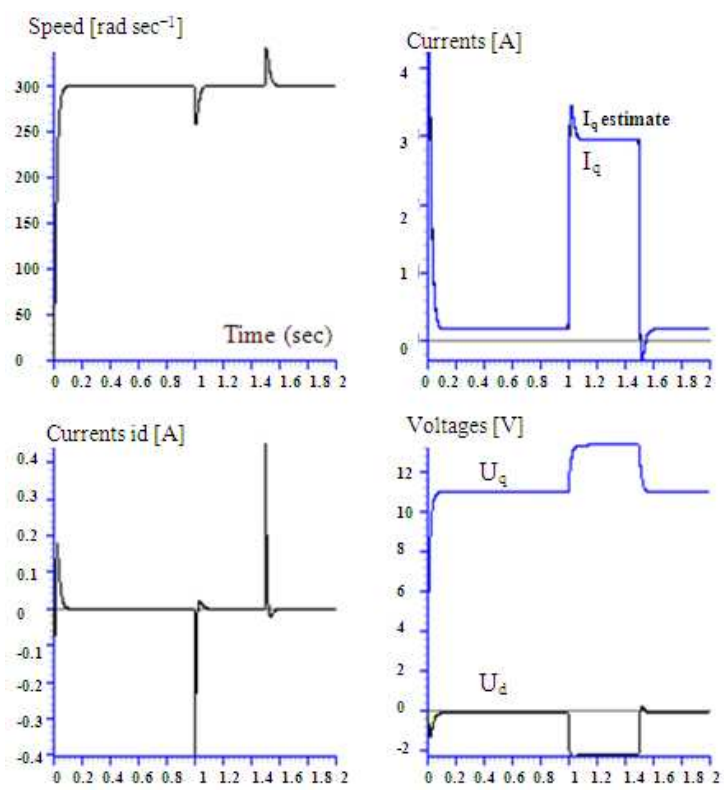

Fig. 4: Simulation of the dynamic behavior of the system without regulation of current and a decoupling with an estimated value of $i_{q}$
Figure 6 shows the response of the system to a step in the position reference from $0-100 \mathrm{Rad}$ and to a positive torque, equal to the rated torque, at $t=1$ sec until $t=1.5 \mathrm{sec}$. The position response is very satisfactory.
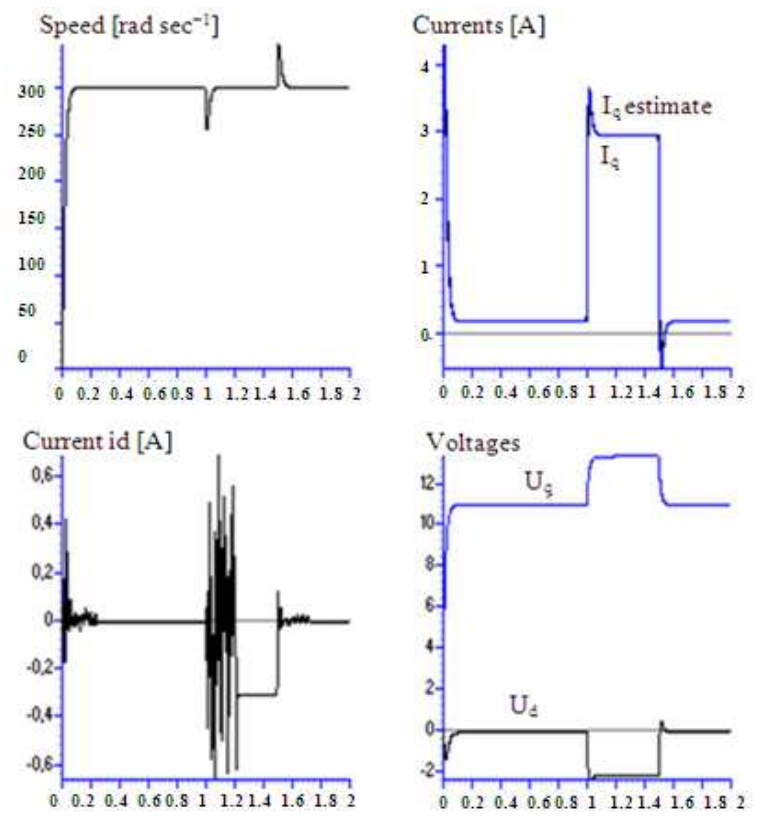

Fig. 5: Simulation of the dynamic behavior of the system without regulation of current and a decoupling with a measured value of $i_{q}$
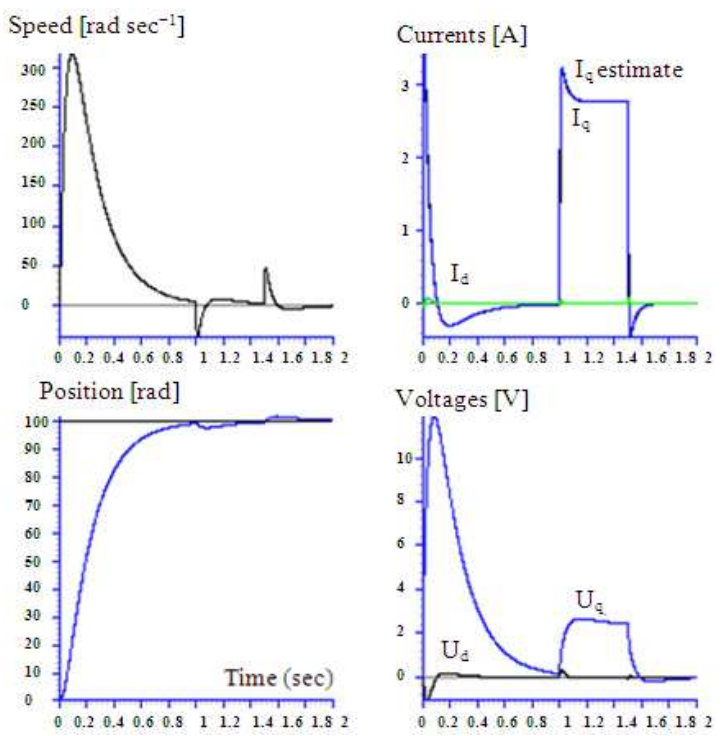

Fig. 6: Simulation of the dynamic behavior of the system to a step in the position reference and to a step in the load torque 
Table 1: Synchronous machine data

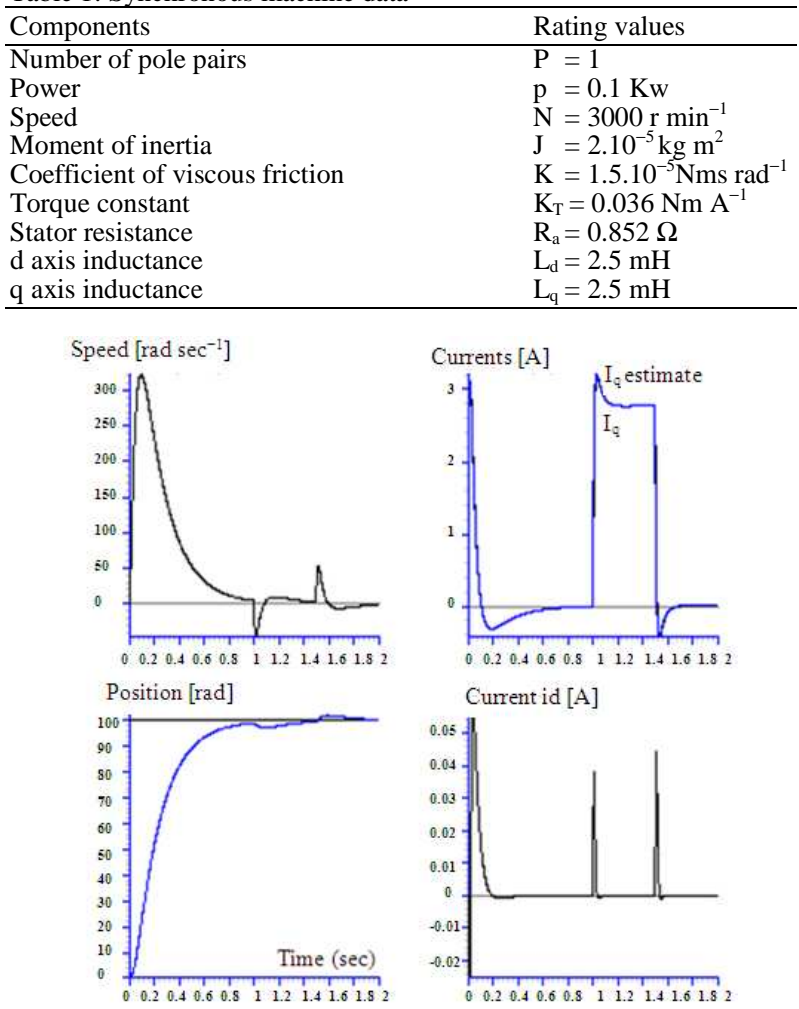

Fig. 7: Simulation of the dynamic behavior of the system when there is an error of $20 \%$ on $\mathrm{R}_{\mathrm{a}}$

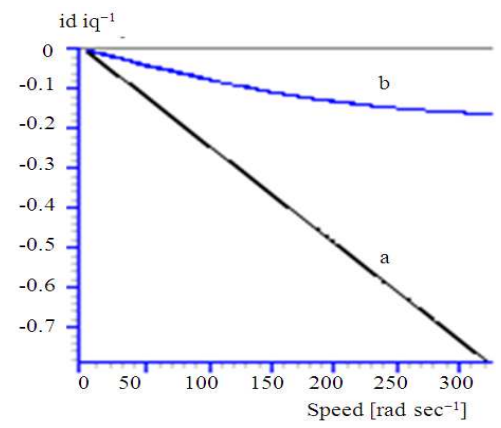

Fig. 8: Error on $i_{d}$ resulting from an error of $20 \%$ on $\mathrm{L}_{\mathrm{q}}$; (a): Decoupling with a measured value of $\mathrm{i}_{\mathrm{q}}$; (b): Decoupling with an estimated value of $\mathrm{i}_{\mathrm{q}}$

Figure 7 shows, respectively, the position, the speed of the rotor of the actuator, currents $i_{d}, i_{q}$, and the estimated current $i_{q}$. In this case an error on parameter $R_{a}$ does not directly affect the control of $i_{d}$ in open loop.

Figure 8 shows the error on $i_{d}$, in function of the speed, when $\mathrm{L}_{\mathrm{q}}{ }^{*}=1.2 \mathrm{~L}_{\mathrm{q}}$, for the actuator considered in the Table 1. It is obvious from Fig. 8 that the effectiveness of the $i_{d}$ control in open loop is greatly improved by the use of an estimated value of $i_{q}$, instead of a measured one.

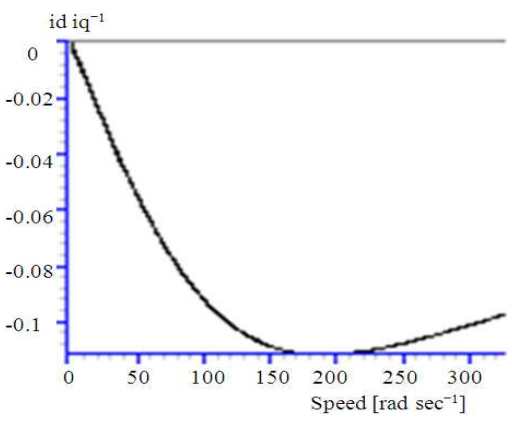

Fig. 9: Error on $i_{d}$ resulting from an error of $25 \%$ on $R_{a}$

Figure 9 shows the error on $i_{d}$ in function of the speed, when $\mathrm{R}_{\mathrm{a}}=1.25 \mathrm{R}_{\mathrm{a}}{ }^{*}$ for the actuator considered in the Table 1.

\section{DISCUSSION}

During the transient due of the step response, the difference between the estimated value of iq and its measured value, which appears in Fig. 4, is mainly due to the delay caused by the computing time. In fact, in order to estimate current iq, by the expression (4), the values of voltage Uq and speed $\omega$ are needed. The value of the voltage Uq, to be applied during the next sampling interval is given at the output of the speed regulator.

As is shown in Fig. 4, the measured value of speed and the estimation of iq are affected by the delay especially when the rotor speed changes very quickly.

Indeed, computing the decoupling feedback as given by the expression (3) with the estimated value of $\mathrm{i}_{\mathrm{q}}$ as given by the expression (4) instead of the measured one has the following advantages:

- The estimation of $\mathrm{i}_{\mathrm{q}}$ gives a one step ahead predicted value of the current

- The estimated value is less noisy than the measured one

- No current measurement is needed, which simplifies the hardware implementation

- The robustness of the decoupling feedback against parameter uncertainties is highly improved

\section{CONCLUSION}

In this study, a model based robust position control scheme for a small power PM synchronous actuator is presented.

It has been proved that the suggested approach based on the introduction of an appropriate decoupling state feedback, presents the advantage to have good 
robustness properties especially when system parameters uncertainties occur because the current values used in the state feedback controller are estimated instead to be measured.

The simplicity of the controller synthesis and implementation is proved by the conducted digital simulation.

\section{REFERENCES}

1. Bin, W., 2006. High Power Converters and AC Drives. John Wiley and Sons, New Jersey, ISBN: 0471731714, pp: 333.

2. Bose, B.K., 2002. Modern Power Electronics and AC Drives. 2nd Edn., Prentice-Hall, New Jersey, ISBN: 10: 013016743.

3. Leonhard, W., 2001. Control of Electrical Drives. 3rd Edn., Pinger Verlag, Berlin, ISBN: 3540418202, pp: 460.

4. Hwakim, K. and M.J. Youn, 2002. A non linear speed control for PM synchronous motor using a simple disturbance estimation technique. IEEE Trans. Ind. Elect., 49: 524-535. DOI: 10.1109/TIE. 2002.1005377
5. Krause, P.C., O. Wasynczuk and S.D. Sudhoff, 2002. Analysis of Electric Machinery and Drive Systems. 2nd Edn., John Wiley and Sons, New York, ISBN: 978-0-471-14326-0, pp: 632.

6. Vas, P., 1990. Vector Control of AC Machines, Clarendon Press, Oxford, ISBN: 0198593708, pp: 352.

7. Gorez, R., D. Galardini and K.Y. Zhu, 1991. Internal model control and disturbance observers. Proceedings of the 30th IEEE Conference on Decision and Control, Dec. 11-13, IEEE Xplore Press, Brighton, pp: 229-235. DOI: 10.1109/CDC.1991.261294

8. Shyu, K.K., C.K. Lai, Y.W. Tsai and D.I. Yang, 2002. A newly robust controller design for the position control of permanent-magnet synchronous motor. IEEE Trans. Ind. Elect., 49: 558-565. DOI: 10.1109/ TIE. 2002.1005380 